\title{
MUNICIPALISMO E SEPARAÇÃO DE PODERES: ANÁLISE DA LEGITIMIDADE DO JULGADO PROFERIDO NA ADO 3.682 E DA EDIÇÃO DA EMENDA CONSTITUCIONAL $57 / 2008$
}

MUNICIPALISM AND SEPARATION OF POWERS: AN ANALYSIS OF THE LEGITIMACY OF THE JUDGMENT PRONOUNCED IN ADO 3.682 AND OF THE EDITING OF CONSTITUTIONAL AMENDMENT 57/2008

MUNICIPALISMO Y SEPARACIÓN DE PODERES: ANÁLISIS DE LA LEGITIMIDAD DEL JUICIO PROFERIDO EN LA ADO 3.682 Y DE LA EDICIÓN DE LA ENMIENDA CONSTITUCIONAL 57/2008

\section{Cynara Monteiro Mariano ${ }^{1}$} Martonio Mont'Alverne Barreto Lima ${ }^{2}$

1 Pós-doutora em Direito Econômico pela Universidade de Coimbra, Doutora em Direito Constitucional pela Universidade de Fortaleza, Mestre em Direito Público e Bacharel pela Universidade Federal do Ceará. Atualmente é Advogada e Professora Adjunta da Universidade Federal do Ceará. E-mail: cynaramariano@gmail.com

2 Doutor e Pós-Doutor em Direito (Rechtswissenschaft) - pela Johann Wolfgang Goethe-Universitat Frankfurt am Main, Mestre em Direito pela Universidade Federal do Ceará e graduado em Direito pela Universidade de Fortaleza. Atualmente é Procurador Geral do Município de Fortaleza, Professor Titular da Universidade de Fortaleza e Coordenador da Área de Direito na CAPES. E-mail: barreto@ unifor.br. 
Resumo: Após a Emenda Constitucional 15/96, os atos de criação, fusão, incorporação ou de desmembramento de Municípios ficaram submetidos a duas novas exigências - a fixação do período, determinado em lei complementar federal, e a realização do estudo de viabilidade municipal, as quais não estavam presentes na redação originária do art. $18, \S 4 .^{\circ}$, da $\mathrm{CF} / 88$. Inobstante, vários Municípios foram criados na Federação brasileira sem cumprir os ditames constitucionais, em especial, a observância do prazo determinado na lei complementar federal, até mesmo em virtude de sua inexistência até os dias atuais. Além de ter declarado a inconstitucionalidade da criação de alguns desses Municípios, o Supremo Tribunal Federal, no julgamento da ADO 3.682, declarou a mora legislativa do Congresso Nacional em editar a citada lei complementar, como também fixou prazo para essa tarefa. Em resposta, o Congresso promulgou a EC 57/2008, convalidando os atos de criação de Municípios sem a referida lei complementar. Dado esse contexto, o presente artigo pretende investigar a legitimidade da atuação da jurisdição constitucional e do Poder Legislativo, analisando se o conflito entre os poderes, nesse caso ou em outros, pode ser resolvido por meio de Emenda Constitucional em sentido contrário às decisões do Supremo Tribunal Federal.

Palavras-chave: Criação de novos Municípios. ADO 3.682. Separação dos poderes. Emenda Constitucional 57/2008.

Abstract: After Constitutional Amendment 15/96, the acts of creation, merger, consolidation or splitting of Municipalities were submitted to two new requirements - the establishment of the period, determined in a supplemental federal law, and the carrying out of a municipal feasibility study, which were not present in the original draft of art. 18, §4. of CF/88. Notwithstanding, several municipalities were created within the Brazilian Federation, without complying with the constitutional precepts, particularly the compliance with deadline set forth in 
the supplemental federal law, even due to its inexistence until today. Besides having declared the unconstitutionality of the creation of some of those municipalities, the Federal Supreme Court, in its judgment of ADO 3.682, declared the legislative delay of the National Congress in editing the aforementioned supplemental law, and established a deadline for this task as well. In response, the Congress promulgated EC 57/2008, validating the acts of creation of Municipalities without this supplementary law. In view of this context, the present article investigates the legitimacy of the action of the constitutional jurisdiction and the Legislative Power, by analyzing whether the conflict among the powers, in this case or in others, may be settled through a Constitutional Amendment that contradicts the decisions of the Federal Supreme Court.

Keywords: Creation of new municipalities. ADO 3.682. Separation of powers. Constitutional Amendment 57/2008.

Resumen: Después de la Enmienda Constitucional 15/96, los actos de creación, fusión, incorporación o de desmembramiento de Municipios quedaron sometidos a dos nuevas exigencias, la fijación del período, determinado por ley complementaria federal, y la realización del estudio de viabilidad municipal, las cuales no estaban presentes en la redacción originaria del art. 18, §4. ${ }^{\circ}$, de la CF/88. No obstante, ya se crearon varios Municipios en la Federación brasileña sin cumplir los dictámenes constitucionales, en especial el cumplimiento del plazo determinado en la ley complementaria federal, incluso en virtud de su inexistencia hasta la actualidad. Además de haber declarado la inconstitucionalidad de la creación de algunos de esos Municipios, el Supremo Tribunal Federal, en el juicio de la ADO 3.682, declaró la mora legislativa del Congreso Nacional en editar la citada ley complementaria, y fijó el plazo para esa tarea. En respuesta el Congreso promulgó la EC 57/2008 convalidando los actos de creación de Municipios 
sin la referida ley complementaria. Dado ese contexto, el presente artículo pretende investigar la legitimidad de la actuación de la jurisdicción constitucional y del Poder Legislativo, analizando si el conflicto entre los poderes, en este caso o en otros, puede ser solucionado por medio de una Enmienda Constitucional en sentido opuesto a las decisiones del Supremo Tribunal Federal.

Palabras clave: Creación de nuevos Municipios. ADO 3.682. Separación de los poderes. Enmienda Constitucional 57/2008.

\section{INTRODUÇÃO}

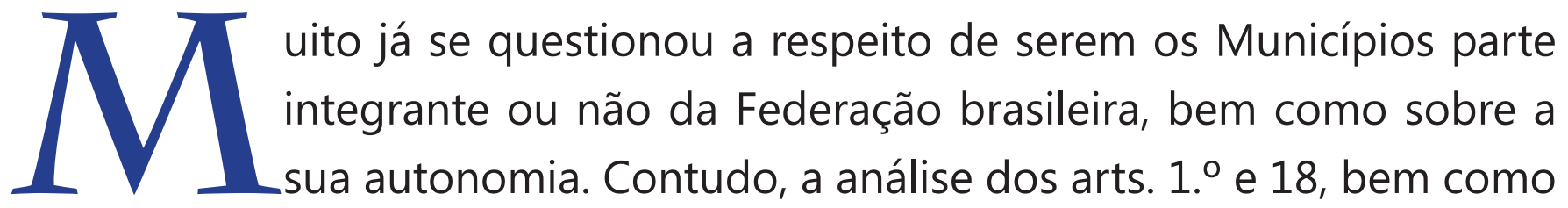
de todo o capítulo reservado aos Municípios, e ainda diante do art. 34, VII, "c", que estabelece a intervenção federal na hipótese de o Estado não respeitar a autonomia municipal, demonstra bem a vontade do constituinte originário de afirmá-los como entes federativos, dotados de autonomia própria, materializada por sua capacidade de auto-organização, autogoverno, autoadministrçaão e autolegislação, em que pesem as vozes dissonantes na doutrina brasileira.

Trata-se, como se sabe, de autonomia e não de soberania. Logo, essa autonomia tem por fundamento e encontra limites na Constituição. No tocante à criação, incorporação, fusão e desmembramento de Municípios na Federação brasileira, é sabido que tais atos não são afetos à competência dos Municípios interessados. O art. 18, § 4. ${ }^{\circ}$ da CF/88, com a redação dada pela Emenda Constitucional 15/96, passou a estabelecer regras mais rígidas para esses procedimentos, obedecendo às seguinte etapas: a) existência de lei complementar federal, determinando o período para a criação, fusão ou desmembramento de Municípios, bem como o procedimento; b) estudo de viabilidade municipal, demonstrando ser possível 
concretamente tais atos; c) realização de plebiscito, como forma de consulta às populações dos Municípios envolvidos, para aprovarem ou não o ato; e d) edição de lei estadual, dentro do período que a lei complementar federal definir.

Pelo teor das prescrições constitucionais, fica claro perceber que os atos de criação, fusão, incorporação ou desmembramento de Municípios, após a edição da EC 15/96, ficaram submetidos a dois novos condicionantes: a fixação do período, determinado em lei complementar federal; e a realização do estudo de viabilidade municipal. Referidas condições não estavam presentes na redação

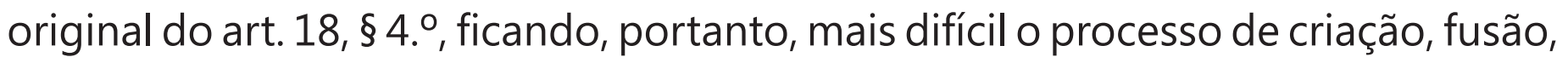
incorporação ou desmembramento de Municípios. Essa, aliás, certamente foi a intenção do constituinte reformador, buscando evitar o surgimento descomedido de novos Municípios, sob o controle exclusivo dos Estados da Federação.

Acontece que até os dias de hoje, como se sabe, o Poder Legislativo não editou a lei complementar federal a que se refere o art. $18, \S 4 .^{\circ}$ da Constituição. Por isso, reconhecendo essa inércia (mais de 10 anos a contar da edição da EC 15/96) no julgamento da Ação Direta de Inconstitucionalidade por Omissão de número 3.682, o Supremo Tribunal Federal, fazendo um "apelo ao legislador", fixou o prazo de 18 meses para que o citado dispositivo constitucional fosse regulamentado. Essa decisão rompeu com o entendimento reinante no âmbito do STF até então, quanto aos efeitos da ADI por omissão, dado que, no caso de a omissão ser imputada ao Poder Legislativo, sua eficácia limitava-se à declaração da mora legislativa, sendo a fixação de prazo para o suprimento da omissão dirigida apenas à Administração Pública.

Antes desse julgado, nas ADI's 2.240, 3.316, 3.489 e 3.689, o Plenário do STF declarou a inconstitucionalidade das leis estaduais que criaram Municípios sem a existência da lei complementar federal, assim exigida pela nova redação do art. 18, $\S 4{ }^{\circ}$, mas não pronunciou a nulidade dos atos, optando por mantendo a vigência do ato de criação por certo tempo, em nítida fixação de efeitos prospectivos.

No entanto, muito provavelmente por ter sentido suas prerrogativas usurpadas por tais decisões, o Congresso Nacional, buscando restaurar o seu espaço político no arranjo institucional da separação dos poderes, assim como visando regularizar 
a situação de alguns Municípios, promulgou a Emenda Constitucional 57/2008, acrescentando o art. 96 ao ADCT, com a seguinte redação: "ficam convalidados os atos de criação, fusão, incorporação e desmembramento de Municípios, cuja lei tenha sido publicada até 31.12.2006, atendidos os requisitos estabelecidos na legislação do respectivo Estado à época de sua criação".

A citada Emenda, obviamente, não afastou a necessidade de edição da lei complementar federal, mas validou a criação retroativa de Municípios, sem a sua existência. Ou seja, pretendeu o Congresso Nacional, mesmo que sob o fundamento de restaurar suas prerrogativas, vulneradas com o julgamento da ADO 3.682, conferir legitimidade a situações criadas em desconformidade à Constituição.

Diante desse quadro, o presente trabalho tem por finalidade analisar a evolução da autonomia municipal no pensamento constitucionalismo brasileiro, bem como a legitimidade do acórdão proferido pelo STF na ADO 3.682 e a iniciativa do Poder Legislativo, consubstanciada na edição da Emenda Constitucional 57/2008. A temática é relevante na medida em que retrata uma situação de claro conflito entre os poderes republicanos e aparentemente sinaliza com a inovação de um forte instrumento (abusivo) de atuação do Poder legislativo nesse confronto, pavimentando um caminho que certamente abalará a democracia e o "princípio esperança", de Ernst Bloch: a edição de Emenda Constitucional em sentido contrário às decisões do Supremo Tribunal Federal.

\section{A REFLEXÃO NACIONAL SOBRE PODER LOCAL E O MUNICÍPIO NO CONSTITUCIONALISMO BRASILEIRO}

A existência de pensamento político municipalista no Brasil, vinculada à forte tradição do poder local na experiência política, contribuiu para a presença determinante da figura do Município na Constituição da República. Constatase, desde a primeira metade do século $X X$, a reflexão municipalista, sendo uma das mais significativas delas o trabalho do antigo ministro do Supremo Tribunal Federal, Victor Nunes Leal, intitulado "Coronelismo, Enxada e Voto - O Município 
e o Regime Representativo no Brasil", publicado pela primeira vez em 1949. Ao qualificar o fenômeno do coronelismo como um sistema "essencialmente governista", o autor diagnostica também a simbiose entre os poderes público e privado, a impedir o desenvolvimento nacional (LEAL, 1986, p. 254). Da mesma forma, estudo paradigmático sobre o poder no Brasil - com destaque para o poder local - é a obra de Raymundo Faoro, "Os Donos do Poder", publicada em 1958. O trabalho de Faoro acentua o caráter patrimonialista das relações de formação do Estado brasileiro, isto é, com determinantes pessoais do exercício do poder, das quais não escapou a esfera local de governo.

Por fim, uma terceira reflexão intelectual sobre poder local é de autoria de Maria Isaura Pereira de Queiroz, "O Mandonismo Local na Vida Política Brasileira", que veio ao público em 1969. Seguindo os passos de seus predecessores, essa autora conclui que a "confusão entre as esferas públicas e privadas" vem a ser também elemento de prova de "apresentarem sempre as lutas municipais muito maior interesse e encarniçamento do que as lutas estaduais e federais" (QUEIROZ, 1969, p. 127).

Em tom inteiramente divergente das reflexões acima mencionadas, não deixa de integrar o pensamento sobre poder local no Brasil a obra de Francisco José de Oliveira Vianna, "Instituições Políticas Brasileiras", publicada sua primeira edição em 1949.

Não há dúvidas de que o primeiro grupo de intelectuais adota postura crítica quanto ao real do universo político-institucional brasileiro, formulando insubstituíveis contribuições - até os dias atuais - a possibilitarem novos rumos constitucionais para o desafio do governo local. Essas reflexões não pouparam as deturpações advindas da prática patrimonialista do governo local, mas nem por isso condenaram a experiência da autonomia do poder local à inexistência ou à absoluta ineficiência. Sem resvalar para o idealismo, pode-se afirmar com alguma segurança que estes pensadores brasileiros - Victor Nunes Leal, Raymundo Faoro, Maria Isaura Pereira de Queiroz - firmaram as bases para a crença de que é possível a instalação da autonomia local, dando-se conta de que será tarefa da institucionalidade brasileira a mitigação de tais desafios. 
Não é o que ocorre com Oliveira Vianna, quando de sua feroz crítica a qualquer ideia de autogoverno municipal; crítica que, até o presente momento de vinte anos de vigência da Constituição Federal, encontra apoio em significativo setor político e intelectual brasileiro. A desconfiança generalizada de Oliveira Vianna quanto ao poder local, ao mesmo tempo em que reconhece - como os outros autores citados - o caráter clânico de nossa política local, conduziu-o ao entendimento de que "não há razão para nos envergonhamos de nossos clãs, de nossa politicagem e dos seus 'complexos' políticos: somos assim porque não podemos deixar de ser assim; e só sendo assim é que poderemos ser como nós somos" (VIANNA, 1987, p. 129).

Enquanto o primeiro grupo de autores intenciona, com suas críticas, a superação da realidade política, Oliveira Vianna adere ao realismo sem a menor vontade transformativa, sem esperança alguma, baseado na crença de que a sociedade brasileira não tinha, definitivamente, qualquer vocação de maturidade política ou desenvolvimento institucional, ainda mais se se tratava dos contornos políticos institucionais em favor dos municípios.

Por fim, outra matriz a contribuir para o pensamento municipalista, agora na sua versão econômica e geográfica, adveio com as publicações dos trabalhos de Aroldo Azevedo, em 1956 ("Vilas e Cidades do Brasil Colonial: Ensaio de Geografia Urbana Retrospectiva"); de Nestor Goulart Reis Filhos (1968: "Evolução Urbana do Brasil"); e de Fany Davidovitch (em 1978, com "Escalas de Urbanização: Uma Perspectiva Geográfica do Sistema Urbano Brasileiro").

Neste universo, a produção de maior impacto talvez venha a ser aquela de Milton Santos, a partir de 1969. A recente reedição, em 2008, de "A Urbanização Brasileira", do mesmo Milton Santos, estabelece novo paradigma, na medida em que apareceu pela primeira vez em 1993, quando o fenômeno do urbanismo brasileiro já estava irreversivelmente consolidado, e assim disciplinado pela então nova Constituição Federal. O fato objetivo de que mais de oitenta por cento da população brasileira habita suas cidades desfaz a origem camponesa da formação constitucional, econômica, política do País, atribuindo um crédito todo especial à obra de Milton Santos. 
Uma visão da parte intelectual do direito a não esquecer os aspectos político, econômico e geográfico do poder local, é a de Eros Roberto Grau, com seu trabalho "Direito Urbano", publicado ainda em 1983, com uma inovadora análise, se se considera as ideias do conjunto dos juristas, para os problemas sempre insolúveis dos grandes conglomerados urbanos, como as regiões metropolitanas e a sua centralidade econômica na vida nacional. Não sem razão, as novas exigências constitucionais adquirem nova força para sua efetividade, com base na vivência do concreto e não na especulação teórica, reforçando a importância de todas estas reflexões.

Consiste, pois, na objetividade desse acúmulo histórico e político nacional o ponto de partida para o delineamento constitucional do Município a que recorreram os trabalhos da Assembleia Nacional Constituinte de 1987/88. Escrevendo uma página do constitucionalismo moderno, a Constituição Federal de 1988 impôs o Município como ente da Federação de forma inequívoca quando da afirmação do caput de seu art. $1^{\circ}$. Não somente assim o qualificou a Constituição, como estabeleceu as diretrizes constitucionais que materializam essa forma de integrar a Federação, nos arts. 29, 29-A, 30 e 31.

Como não há um tipo ideal de federação (BERCOVICI, 2003, p. 145), cada realidade concreta das experiências de organizações políticas estatais pode decidir por seu federalismo, sendo importante a existência de distintos centros de poder, a se localizarem hierarquicamente no mesmo nível, porém dotados de esferas distintas de atuação, vale dizer, de competências diferenciadas. Assim, a federação nada mais é do que uma maneira de organização estatal a admitir o conflito, na medida em que convivem autônomos centros de decisão administrativa e política. O que garante a unidade na federação é, porém, a previsão normativa constitucional de como tais conflitos serão resolvidos sem a continuidade do comprometimento e da convivência do todo nacional.

O Município, na sua condição de ente federativo brasileiro, possui suas competências delineadas, sejam elas no território da discussão políticoadministrativa, sejam no âmbito das disputas a aterrissarem nas instâncias do Poder Judiciário, em virtude dos conflitos de atuação legislativa e executiva 
que a constituição dirigente tem imposto aos distintos componentes da Federação brasileira. Desta forma é que, apesar do entendimento do princípio da subsidiariedade na qual pontifica a ideia de que "se deve dar preferência à unidade social menor, em lugar da maior" (BARACHO, 1997, p. 49), como elemento fortalecedor do pacto federativo, a questão da competência municipal, como no caso da suplementação da legislação federal e estadual no que couber (art. 30, II da Constituição Federal), permanece indefinida. Essa indefinição tem representado não raramente o principal momento causador da consolidação do pacto federativo brasileiro, na medida em que disputas judiciais arrastam todas as entidades federativas à inação ou a superposição de ações, a desembocarem em autênticos dramas administrativos e políticos.

Mesmo com essas digressões, e a imposição explícita do art. $1^{\circ}$ da Constituição Federal, não são sem importância vozes a afirmarem que o Município não é entidade da Federação. É o caso de José Nilo de Castro. Para esse autor, o Município não tem representação no Senado, não possui Tribunal de Contas - "salvo São Paulo e Rio" (CASTRO, 2002, p. 53), não pode propor emendas à Constituição, não tem suas normas sujeitas ao controle concentrado diretamente perante o Supremo Tribunal Federal, nem tem Poder Judiciário. Essas ausências impossibilitam ao Município sua condição de entidade da Federação, além de, segundo o mesmo pensamento, inexistir pacto federativo com Município.

Ora, as distinções entre Estados e Municípios foram estatuídas pela mesma Constituição Federal. O que se deu é que a vontade constituinte decidiu incluir o Município em grau federativo idêntico àquele da União, Estados-Membros e Distrito Federal, guardando, entretanto, a peculiaridade municipal. Está-se diante, então, de exceção autorizada pelo mesmo nível hierárquico normativo, qual seja, a mesma Constituição. Como não se dispõe de um conceito válido universalmente de federalismo, cada sociedade pode organizar seu federalismo da melhor maneira a lhe indicarem suas características culturais, econômicas, histórico-geográficas, sociais e políticas. Parece completamente sem razão, assim, a tese defendida por José Nilo de Castro, representando sua posição um entendimento que a poucos tem seduzido ${ }^{3}$.

3 Conferir, nesse sentido, COSTA, 2002, pp. 97ss. 
No que diz respeito especificamente ao controle concentrado da constitucionalidade de normas municipais em abstrato perante oSTF, interessantes e novos parâmetros têm surgido no cenário jurídico constitucional brasileiro, especificamente após a Lei $n^{\circ}$ 9.882, de 3 de dezembro de 199, que veio regulamentar a arguição de descumprimento de preceito fundamental (ADPF), prevista pelo $\S 1^{\circ}$ do art. 102 da Constituição da República (TAVARES, 2001, pp. 150ss). Nesse sentido, destaca Gilmar Ferreira Mendes (2007, p. 70) que:

(...) subsistia, porém, ampla insegurança, em razão da falta de um mecanismo expedito de controle da constitucionalidade do direito municipal perante a Constituição Federal. Deve-se observar, outrossim, que, dada a estrutura diferenciada da Federação brasileira, algumas entidades comunais têm importância idêntica, pelo menos do prisma econômico e social, à de muitas entidades federadas, o que conferira gravidade à ausência do controle normativo eficaz (grifos nossos).

Assim é que, em virtude da importância econômica e política de alguns dos Municípios brasileiros, a atenção do STF tem sido chamada - tanto quanto em episódios que envolvem determinados Estados-Membros - quando se trata de questão do controle direto da constitucionalidade das leis municipais, amparado pela previsão normativa do inciso I do art. $1^{\circ}$ da Lei $n^{\circ}$ 9.882/99, que estabeleceu o cabimento de ADPF quando se tratar também de controvérsia sobre lei ou ato normativo federal, estadual ou municipal ${ }^{4}$.

Em que pese, portanto, a possibilidade atual de os Municípios terem suas normas sujeitas ao controle concentrado diretamente perante o Supremo Tribunal Federal, o que torna desmerecida a crítica de José Nilo de Castro, a eles, no entanto, ainda não é facultado decidir com exclusividade sobre determinadas matérias de seu interesse, a exemplo dos próprios atos de fusão, cisão, incorporação ou desmembramento, que constituem tema do presente artigo.

Pelo teor do art. $18, \S 4 .^{\circ}$ da CF/88, tais atos encontram-se condicionados ao exercício da competência dos outros dois entes Federados: à União Federal, para a edição da lei complementar, determinando o período para a criação, fusão ou desmembramento de Municípios, bem como o procedimento; e aos Estados, para 4 Em sentido da inconstitucionalidade deste dispositivo legal, v.: ROCHA, 2002, p. 112. 
a edição de lei estadual, dentro do período que a lei complementar federal definir, para a realização de plebiscito, como forma de consulta às populações locais, para aprovarem ou não o ato, e para a elaboração de estudos de viabilidade municipal.

Logo, para tal procedimento, o constituinte originário agora exige a participação conjunta de dois dos três integrantes da Federação, o que parece não ter sido bem observado nos atos de criação e desmembramento de vários Municípios brasileiros, mesmo após a Emenda Constitucional 15/96, resultando no julgamento de procedência das ADI's 2.240, 3.316, 3.489 e 3.689 e da ADO 3.682, pelo Supremo Tribunal Federal, como adiante será retratado.

\section{O CONFLITO ENTRE OS PODERES INSTAURADO COM A ADO 3.682 E A EDIÇÃO DA EMENDA CONSTITUCIONAL 57/2008: SOLUÇÃO DEMOCRÁTICA?}

Ainda sobre a autonomia municipal e o lugar de relevo que os Municípios ocupam hoje na Federação brasileira, é importante analisar um caso recente em que essa autonomia foi objeto de conflito entre os poderes legislativo e judiciário, resultando em um giro hermenêutico acerca da eficácia de um importante instrumento de controle de constitucionalidade, a saber, a Ação Direta de Inconstitucionalidade por Omissão (ADO), e na edição de uma polêmica Emenda Constitucional.

Conforme já relatado em linhas anteriores, em virtude da inércia do Congresso Nacional, que se prorroga até os dias atuais, o Supremo Tribunal Federal, no julgamento da ADO 3.682, fazendo um "apelo ao legislador", fixou o prazo de 18 meses para que a lei federal, a que se refere o art. $18, \S 4 .^{\circ}$, da CF/88, fosse regulamentada.

Até então, no âmbito da hermenêutica constitucional, em respeito ao princípio da separação dos poderes, não era permitido ao STF, em sede de ADO, elaborar a lei, suprindo a omissão legislativa, ou fixar prazo para a sua elaboração, na hipótese de a omissão ser imputada ao Poder Legislativo. Isso porque o art. $103, \S 2 .^{\circ}$ da CF/88 estabelece efeitos diversos, quando a omissão for do "poder competente" ou do "órgão administrativo". No primeiro caso, é dada ciência ao 
poder competente da sua omissão, não se estabelecendo qualquer prazo para a elaboração da lei. No segundo, o STF pode determinar o prazo de trinta dias para que o órgão administrativo supra a omissão, sob pena de responsabilidade. Ainda nos termos do art. $12-\mathrm{H}, \S 1^{\circ}$, da Lei 9.868/99, é também possível a fixação de um prazo razoável, a ser determinado excepcionalmente pelo STF, tendo em vista situações específicas e o interesse público presente no caso.

Obviamente, sempre houve interpretações divergentes quanto ao alcance do art. 103, § 2..$^{\circ}$ da CF/88. Uma dessas interpretações resultou justamente na polêmica decisão tomada pelo Supremo Tribunal Federal, nos autos da ADO 3.682. Acompanhando o voto do relator, o ministro Carlos Britto, por exemplo, assim observou:

(...) diferentemente da Constituição portuguesa, a nossa não se limitou a cuidar da ADI por omissão de medida legislativa; foi além. Quando a nossa Constituição falou em dar ciência ao poder competente, claro que mais de um poder, não só ao Poder Legislativo, apenas a Constituição avançou o comando de que, em se tratando de órgão administrativo, esse prazo seria de trinta dias, mas sem com isso excluir a possibilidade de se fixar um prazo, logicamente, maior para o Poder Legislativo.

Convictos, assim, de que a melhor exegese a ser aplicada na espécie era a de conferir caráter nitidamente mandamental à decisão, mesmo que dirigida ao Poder Legislativo, os ministros do Supremo Tribunal Federal resolveram julgar a ação procedente:

(...) para declarar o estado de mora em que se encontra o Congresso Nacional, a fim de que, em prazo razoável de 18 (dezoito) meses, adote ele todas as providências legislativas necessárias ao cumprimento do dever constitucional imposto pelo art. $18, \S 4 .^{\circ}$, da Constituição, devendo ser contempladas as situações imperfeitas decorrentes do estado de inconstitucionalidade gerado pela omissão. Não se trata de impor um prazo para a atuação legislativa do Congresso Nacional, mas apenas da fixação de um parâmetro temporal razoável, tendo em vista o prazo de 24 meses determinado pelo Tribunal nas ADI's 2.240, 3.316, 3.489 e 3.689 para que as leis estaduais que criam municípios ou alteram seus limites territoriais continuem vigorando, até que a lei complementar federal seja promulgada contemplando as realidades desses municípios (ADO 3.682, rel. Min. Gilmar Mendes, j. 09.05.2007, DJU 06.09.2007). 
Houve, portanto, uma mudança clara de entendimento acerca dos efeitos da decisão proferida em sede de Ação Direta de Inconstitucionalidade por Omissão, que deixou de se limitar, quanto ao Poder Legislativo ou quanto aos demais poderes, à declaração e à ciência da mora, para abranger a possibilidade de fixação de prazo para suprir a omissão. Além desse novo caráter mandamental, a decisão proferida pelo STF na ADO 3.682, ao fixar o prazo de 18 meses para que a lei complementar federal fosse regulamentada pelo Congresso Nacional, "tendo em vista o prazo de 24 meses determinado pelo Tribunal nas ADI's 2.240, 3.316, 3.489 e 3.689 para que as leis estaduais que criam municípios ou alteram seus limites territoriais continuem vigorando, até que a lei complementar federal seja promulgada contemplando as realidades desses municípios", também imprimiu ao julgado a técnica da "inconstitucionalidade progressiva" ou da "declaração de constitucionalidade de norma em trânsito para a inconstitucionalidade", de origem do Tribunal Constitucional federal alemão. ${ }^{5}$

De qualquer forma, isso quer dizer que, findo o aludido prazo de 24 meses (dentro do qual o Congresso Nacional deveria editar a LC federal em 18 meses), os atos de criação e desmembramento de Municípios efetivados pela Lei 7.619/2000, do Estado da Bahia (que criou o Município Luis Eduardo Magalhães), pela Lei 6.983/98, do Estado do Mato Grosso (que criou o Município de Santo Antônio do Leste, a partir de área desmembrada do Município de Novo São Joaquim), pela Lei 12.294/2002, do Estado de Santa Catarina (que anexou ao Município de Monte Carlos a localidade de Vila Arlete, desmembrada do Município de Campos

5 Essa técnica, que permite considerar a lei em causa como constitucional durante certo tempo, após o qual se torna inconstitucional, foi adotada pelo STF no julgamento do HC 70.514, em 23.03.1994, ao analisar a questão do prazo em dobro para a Defensoria Pública no processo penal, instituído pelo $\S 5 .^{\circ}$ do art. $1 .^{\circ}$ da Lei 1.060 , de 05.02.1950, acrescentado pela Lei 7.871, de 08.11.1989. A adoção dessa técnica pode ser vislumbrada pelo seguinte trecho do voto do ministro Moreira Alves: "a única justificativa que encontro para esse tratamento desigual em favor da Defensoria Pública em face do Ministério Público é a de carácter temporário: a circunstância de as Defensorias Públicas ainda não estarem, por sua recente implantação, devidamente aparelhadas como se acha o Ministério Público. Por isso, para casos como este, parece-me deva adotar-se a construção da Corte Constitucional alemã no sentido de considerar que uma lei, em virtude das circunstâncias de fato, pode vir a ser inconstitucional, não o sendo, porém, enquanto essas circunstâncias de fato nãos e apresentarem com a intensidade necessária para que se tornem inconstitucionais. Assim, a lei em causa será constitucional enquanto a Defensoria Pública, concretamente, não estiver organizada com a estrutura que lhe possibilite atuar em posição de igualdade com o Ministério Público, tornando-se inconstitucional, porém, quando essa circunstância de fato não mais se verificar". 
Novos) e pela Lei 6.066/97, do Estado do Pará (que desmembrou faixa de terra do Município de Água Azul do Norte, integrando-a ao de Ourilândia do Norte), perderiam sua validade.

Pensa-se, contudo, que, nesse caso, a decisão tomada na ADO 3.682 aparenta ter sido tomada mais pelo calor da irresignação da opinião pública ou da sociedade em geral, quanto ao lento e muitas vezes desidioso processo legislativo de elaboração das leis, e menos em virtude de um amadurecimento hermenêutico em si. Do voto do ministro relator, Gilmar Mendes, extrai-se o seguinte trecho:

(...) apesar de existirem no Congresso Nacional diversos projectos de lei apresentados visando à regulamentação do art. 18, §4, da Constituição, é possível constatar a omissão inconstitucional quanto à efectiva deliberação e aprovação da lei complementar em referência. As peculiaridades da actividade parlamentar que afetam, inexoravelmente, o processo legislativo, não justificam uma conduta manifestamente negligente ou desidiosa das Casas Legislativas, conduta esta que pode pôr em risco a própria ordem constitucional. A inertia deliberandi das Casas legislativas pode ser objeto da ação direta de inconstitucionalidade por omissão. A omissão legislativa em relação à regulamentação do art. 18, §4, da Constituição, acabou dando ensejo à conformação e à consolidação de estados de inconstitucionalidade que não podem ser ignorados pelos legislador na elaboração da lei complementar federal.

É verdade que no caso da edição da lei complementar federal a que se refere o art. 18, § 4, da Constituição, o Poder Legislativo vem sendo omisso. É verdade também que essa omissão afronta a Constituição. Contudo, não é menos verdade que essa omissão é insuficiente para legitimar a atuação da jurisdição constitucional nessa situação. A eventual morosidade do legislativo não autoriza a transferência da decisão parlamentar para os tribunais. Afinal, não se pode esperar do legislativo que tome as decisões na mesma velocidade que os tribunais, pois o Parlamento é fruto, na sua essência, de todos os antagonismos políticos, culturais, sociais e econômicos existentes na sociedade brasileira. Não é fácil, portanto, muito menos célere, o processo de deliberação no âmbito parlamentar.

Nesse sentido, Ingeborg Maus, na obra O direito e a política (2009), já alertou que essa transferência do centro de decisão para os tribunais, quer sob o 
fundamento de inércia do legislativo, quer sob o fundamento de imprecisão ou indeterminação do conteúdo da lei, fragiliza a democracia na medida em que abala fortemente a separação dos poderes.

Assim, em que pesem as razões que levaram a esse giro hermenêutico no julgamento da ADO 3.682, com as quais aqui se concorda apenas em parte, certo é que a decisão do STF afrontou a separação dos poderes. A inércia do Congresso Nacional quanto à edição da lei complementar federal a que se refere o art. 18, $\S 4 .^{\circ}$ da CF/88 não justifica nem autoriza a intervenção do judiciário. A omissão legislativa não diz respeito, nesse caso, ao exercício de direitos fundamentais, mas ao período e às regras procedimentais para os atos de criação, fusão, incorporação ou desmembramento de Municípios. Embora a Constituição não qualifique propriamente a natureza da omissão passível de controle pela via da ADO, como faz no caso do mandado de injunção, a intervenção do judiciário, porque grave e excepcionalíssima, somente se legitimaria na ADO na hipótese em que a omissão do Poder Legislativo frustrasse o exercício de direitos fundamentais, o que não se acredita tenha sido o caso.

A respeito dessa restrição à atuação do judiciário, adepto da teoria do selfrestraint, John Hart Ely, em Democracy and Distrust, afirma que a atuação da jurisdição constitucional deve se limitar a assegurar o processo democrático e a proteção dos direitos fundamentais, de modo que a escolha dos valores substanciais agasalhados na Constituição não é prerrogativa de um tribunal constitucional, mas sim dos representantes do povo (ELY, 1980, p. 103). Da mesma forma, Cass R. Sunstein (1996, p. 7) também entende que:

(...) no governo americano e nas democracias constitucionais que funcionam a contento, o real fórum para a deliberação sobre os mais importantes princípios políticos não é o judiciário - a maioria dos princípios fundamentais são desenvolvidos democraticamente, não em courtrooms.

Por isso, muito provavelmente para reagir contra essa atuação do Supremo Tribunal Federal na ADO 3.682, o Congresso Nacional promulgou a Emenda Constitucional 57, de 18.12.2008, buscando convalidar o vício formal de todas 
as referidas leis estaduais que criaram e desmembraram Municípios sem a observância do art. $18, \S 4 .^{\circ}$ da Constituição. Apesar de sua reação contra essa investida do judiciário, não se pensa, porém, que a edição de uma Emenda Constitucional tenha sido o melhor caminho. O exercício do poder constituinte derivado, por alterar a vontade do poder constituinte originário, também deve ser excepcional. Ele não se presta como instrumento de combate no conflito entre os poderes. Sua atuação só é legítima na medida em que se direciona a atualizar o sentido da Constituição em conformidade aos reclamos sociais e da vida política, como se infere do conceito de uma Constituição Aberta, de J. J. Gomes Canotilho (2003, p. 1339).

É certo que o legislativo possui a prerrogativa de exercer o controle de constitucionalidade das próprias leis editadas e que isso pode se dar não apenas por meio do controle preventivo realizado no interior do procedimento legislativo. Se lex posteriori derrogat priori, por ser manifestação mais recente da vontade do legislador, basta que esse legislador a manifeste para eliminar eventual lei inconstitucional. Se essa ocorrência se dá por motivos políticos ou como resultado da jurisdição constitucional, isso é irrelevante, já que o resultado de ambas é idêntico, a saber, a eliminação da incompatibilidade com a Constituição (MARIANO, 2010, p. 205).

Todavia, se a eliminação da inconstitucionalidade ocorre como resultado da jurisdição constitucional, seguida de uma reação política contra essa investida, e ainda para legitimar a própria inconstitucionalidade, como ocorreu com a edição da EC 57/2008, o fato é preocupante. Isso pode até ser legalidade, mas nem de longe é legítimo. O legislativo perde a sua legitimidade se atenta contra a própria Constituição. Assim como também perde a legitimidade se, fazendo uso da soberania de poder constituinte derivado, age casuisticamente, desnaturando a finalidade da Emenda Constitucional e seus destinatários.

Logo, não basta ao legislativo agir na qualidade de poder constituinte (derivado). A vinculação de sua atuação a conteúdos legítimos também o obriga. Do contrário, como adverte Friedrich Müller, "não importassem os conteúdos da ação estatal considerada 'legítima', 'Constituição 'não seria um conceito jurídico, 
mas apenas um suporte fático existencial, apenas 'vontade e 'decisão`." (MÜLLER, 2004, p. 114).

\section{CONCLUSÃO}

Se se quer, nesse contexto, enfrentar a crítica conservadora, não há como se deixar de trabalhar de forma realista e em conformidade com o dirigismo da Constituição Federal a problemática da esperança, como potencial emancipatório da consciência de uma sociedade e de seus representantes políticos. Aqui, a referência ao "princípio esperança", formulado por Ernst Bloch em 1955, vem oferecer interessante visão analítica.

Ernst Bloch publicou, na extinta República Democrática Alemã, seu trabalho de mais 1.500 páginas, "O Princípio Esperança"6, obra que o fez membro da Academia de Ciências de Berlim 7 . A esperança concebida por Bloch trata da energia humana traduzida pela paixão do êxito sobre o fracasso. A esperança, nessa vertente, nada tem de idealista, passando a significar o querer como superação do desejo, na medida em que aquele concretiza a pulsão pela vida e pelo fazer, enquanto este possui em seu núcleo a passividade (ou mesmo a angústia do arrependimento):

Porém, por mais intenso que seja, neste ponto o desejar se diferencia do querer propriamente dito por seu modo passivo, ainda parecido com o ansiar. No desejar não há nada de trabalho ou atividade. Em contrapartida, todo querer é um querer-fazer. (...) Aquele que quer, ao contrário, já estabeleceu uma preferência: sabe o que prefere, a escolha ficou para trás., (...) O querer, ao contrário, é necessariamente um avançar ativo rumo a esse alvo, dirige-se para fora, tem de se medir unicamente com coisas realmente dadas" (BLOCH, 2005, p. 50-51).

A energia a movimentar a esperança é, dessa forma, o querer, a ação, sempre para frente, em direção aos objetivos que se impõem perante o homem em sociedade. Daí deriva a crítica de Bloch a Hegel e a Freud.

6 Das Prinzip Hoffnung, no original, publicado em 1959, na República Federal da Alemanha, pela editora Suhrkamp, Frankfurt/M.

7 CALDWELL, Peter C.: Dictatorship, State Planning and Social Theory in the German Democratic Republic. Cambridge: Cambridge University Press, 2003, p. 122. 
Para Bloch, o primeiro olha para o passado, a fim de imobilizar o presente - e o futuro - na forma ideal do que é: "aquilo que é racional, isto é o real; e o quê é real, este é o racional" (HEGEL, 1995, p. 14) ${ }^{8}$. Freud representa, para Bloch, o pensamento do presente, sem igualmente considerar o futuro. $O$ futuro, 0 infinito vir-a-ser é de Marx, que conclamou a todos os homens do mundo numa perspectiva universalista. Pois desta forma é que devem ser compreendidos, por exemplo, os direitos fundamentais, numa possibilidade emancipatória. Liberdade de expressão de pensamento, de reunião, direito de greve não deveriam ser objetos de garantia. Não se trata, sob essa ótica e para Bloch, sobre direito "de" alguma coisa, mas de direito "para", "em direção" a alguma coisa. Assim é que a "liberdade final" seria uma liberdade que não se oporia à ordem, mas seria dela parte, "uma ordem concebida numa sociedade pura e simplesmente não coercitiva, de uma estrutura não antagônica" (CALDWELL, 2003, p. 129)9.

A Constituição Federal de 1988 é também um documento da esperança, o que se deixa provar pelo "querer-fazer" de suas determinações. É lugar-comum a afirmação de que o nosso texto constitucional não simboliza simplesmente um "catálogo" de boas intenções. Portanto, não seria, na linguagem de Ernst Bloch, um pueril desejar, alimentado pela angústia da imobilização. O interessante é que os discursos contrários à Constituição, de base normativista e conscientemente idealistas, não cansam de repetir o espontaneísmo de que "a Constituição foi aviltada", ou de que nada se fez no País nos últimos vinte anos, ou ainda apelar para a sofisticada "morte da constituição dirigente". Com este status quo discursivo liquida-se tanto o potencial do "querer-fazer" da Constituição, como ainda se ilude sobre quem veicula tal discurso, na medida em que este ator intelectual ou político aparecerá, geralmente, como venerável e velho sábio, crítico do marasmo e da ineficiência da Constituição da República. Assim, "mudamos alguma coisa para que nada mude", como está disseminada esta ideia em parte significativa da esperta cultura política brasileira!

Assimilar a ordem constitucional brasileira de 1988 aos dias atuais não consiste em um fácil exercício de retórica, mas em um desafio de ter em mente que sua efetivação dependerá da sociedade brasileira e de seus esforços. Excluir a 8 No original: "Was vernünfitg ist, das ist wirklich; was wirklich ist, das ist vernünftig".

9 No original: "(...) an order conceived of as "an uncoerced structure of non-antagonistic society pure and simple". 
sociedade dessa tarefa, relegando-a a atores intelectuais e políticos, somente servirá ao deleite dos que sempre mandaram e mantiveram seus privilégios, numa sociedade herdeira não somente a escravidão; mas herdeira de uma perene cultura da escravidão. A esperança que se substitui ao fracasso à implementação do texto constitucional brasileiro será, a priori, a aceitação de que este texto constitucional veio para mudar.

Desse modo, aplicar critérios interpretativos da hermenêutica, como ocorreu no julgamento da ADO 3.682, ou recorrer ao exercício do poder constituinte derivado, com a edição da EC 57/2008, como fórmula de resolução dos conflitos em uma sociedade de extrema desigualdade como a brasileira coincide com o cancelamento da esperança constitucional. As dificuldades da implementação constitucional não decorrem da distância entre seu texto e a objetiva realidade brasileira. Decorrem bem mais do comportamento dos atores intelectuais e políticos em bloquear suas inovações estruturais, seja no plano nacional, seja no internacional. Aqui, o argumento da "morte da constituição dirigente", surgido nos últimos cinco anos, ganha força toda especial contra a constituição da realista esperança.

Não sem razão que o desafio federativo sobre o poder local - na sua condição de inovação constitucional e de confiança futura no sucesso da chegada do Estado dirigente também naquela primeira esfera da vida dos cidadãos - encontra-se desacreditado, embora o ditame constitucional não deixe espaço para questionamentos sobre sua natureza positiva. Por isso que a disposição no reafirmar da viabilidade do governo pelo poder local - como instância de ratificação do Estado constitucional, democrático e dirigente nada mais corresponde do que a convergência com a esperança que nosso texto constitucional de 1988 trouxe.

\section{REFERÊNCIAS}

BARACHO, José Alfredo de Oliveira. O Princípio da Subsidiariedade. São Paulo: Ed. Forense, 1997.

BERCOVICI, Gilberto. Desigualdades Regionais, Estado e Constituição. São Paulo: Max Limonad, 2003. 
BLOCH, Ernst. O Princípio Esperança. Rio de Janeiro: Ed. Contraponto/Ed. da Universidade Estadual do Rio de Janeiro, v. 1, 2005.

CALDWELL, Peter C. Dictatorship, State Planning and Social Theory in the German Democratic Republic. Cambridge: Cambridge University Press, 2003.

CANOTILHO, J. J. Gomes. Direito Constitucional e Teoria da Constitucional. 7. ed. Coimbra: Almedina, 2003.

CASTRO, José Nilo. Direito Municipal Positivo. Belo Horizonte: Ed. Del Rey, 2002.

ELY, John Hart. Democracy and distrust. A theory of judicial review. Cambridge, Massachusetts: Harvard University, 1998.

HEGEL, Georg Wilhelm Friedrich. Grundlinien der Philosophie des Rechts. In: G.W.F. Hegel; Hauptwerke in sechs Bänden. Darmstadt: Wissenschaftliche Buch-gesellschaft, Bd. 5, 1995

LEAL, Victor Nunes. Coronelismo, Enxada e Voto. São Paulo: Alfa-Ômega, 1986.

MARIANO, Cynara Monteiro. Legitimidade do direito e do poder judiciário. Neoconstitucionalismo ou poder constituinte permanente? Belo Horizonte: Del Rey, 2010.

MAUS, Ingeborg. O direito e a política: Teoria da democracia. Tradução: Elisete Antoniuk. Belo Horizonte: Del Rey, 2009.

MENDES, Gilmar Ferreira. Arguição de Descumprimento de Preceito Fundamental. Comentários à Lei n 9.882, de 3-12-1999. Série IDP. Saraiva: São Paulo, 2007.

MÜLLER, Friedrich. Fragmento (sobre) o poder constituinte do povo. Tradução: Peter Naumann. São Paulo: Revista dos Tribunais, 2004.

QUEIROZ, Maria Isaura Pereira de. O Mandonismo Local na Vida Política Brasileira. São Paulo: Instituto de Estudos Brasileiros da Universidade de São Paulo, 1969.

ROCHA, Fernando Luiz Ximenes. Controle de Constitucionalidade das Leis Municipais. Atlas: São Paulo, 2003.

SUNSTEIN, Cass R. Legal reasoning and political conflict. New York: Oxford University Press, 1996.

TAVARES, André Ramos. Tratado da Argüição de Preceito Fundamental. São Paulo: Saraiva, 2001.

VIANNA, Fco. José de Oliveira. Instituições Políticas Brasileiras. Belo Horizonte/Rio de Janeiro/São Paulo: Ed. Itatiaia/Ed. da Universidade Federal Fluminense/Ed. da Universidade de São Paulo, vol. 1, 1987. 